\title{
A PERCEPÇÃO SEGUNDO BARBARAS
}

\section{Leandro Neves Cardim*}

Resumo: Este artigo pretende apresentar o conceito de percepção assim como o interpreta o filósofo francês Renaud Barbaras. Ele parte da recolocação do problema da percepção entre imanência e transcendência para indicar os traços fundamentais que caracterizam este fenômeno segundo seu próprio ponto de vista: o sujeito da percepção como sujeito vivo e a essência da vida como desejo. Não se trata, para ele, de aproximar-se da percepção através daquilo que ela não é. Para compreender verdadeiramente a percepção é preciso nos deixar formar junto à própria experiência perceptiva, ou antes, é preciso pensar segundo a própria percepção.

Palavras-chave: Barbaras, percepção, movimento, desejo, vida.

O tema da percepção é antigo no percurso filosófico de Renaud Barbaras. Se fosse o caso de traçar a sua gênese seria interessante rastrear sua eclosão desde seu livro pioneiro Do ser do fenômeno. Sobre a ontologia de Merleau-Ponty de 1991, mas isto exigiria um tempo extra que não podemos dispor aqui. Dentre vários outros textos publicados sob o signo da percepção, há dois que especialmente nos interessam: $A$ percepção. Ensaio sobre o sensível publicado pela primeira vez em 1994, e O desejo e a distância. Introdução a uma fenomenologia da percepção de 1999. ${ }^{1}$ Através de seu trabalho sobre a percepção, o autor se lança na vida filosófica não só como intérprete da história da filosofia, mas, sobretudo, como alguém que exprime seu próprio ponto de vista posicionando-se em relação à tradição filosófica: ele reformula o problema da percepção de tal modo que a solução que surge de suas páginas aponta para novos horizontes abertos por sua própria interrogação filosófica.

* Departamento de Filosofia da Universidade Federal do Paraná. E-mail: lnc@ufpr.br. 
Aqui, pretendo apenas delinear a interpretação fornecida por Renaud Barbaras do sujeito da percepção como sujeito vivo e da essência da vida como desejo. Para ele é preciso uma interpretação da vida que dê conta do enraizamento tanto da percepção quanto do conhecimento no seio da própria vida. Neste contexto, a consciência humana se revela uma possibilidade da vida, ou antes, a vida surge como a "verdadeira condição de possibilidade" da consciência (Barbaras 8, p. 7). Para compreendermos isto é preciso "pensar a percepção a partir da vida" (Barbaras 3, p. 23). Mas, antes de chegar aí, devemos indicar, inicialmente, que a percepção como modo de acesso ao mundo de objetos exteriores exige uma filosofia especial que não se contente em estudar a percepção "como um setor do Ser dentre outros" (Barbaras 4, p. 28). Trata-se, ao contrário, de fazer experiência da percepção em sua singularidade e retificar os instrumentos filosóficos através dos quais tal experiência deve ser reinterpretada. A verdadeira filosofia da percepção é uma filosofia para a qual "o objeto percebido libera o sentido de ser de todo ser" (Barbaras 12, p. XVI). Se for verdade que a tradição filosófica ao mesmo tempo perde a especificidade da experiência perceptiva e oculta seu sentido original, compreende-se a razão graças à qual, segundo Barbaras, “a tarefa de uma filosofia da percepção não é tentar se apropriar da percepção a partir de categorias de que ela dispõe, mas, antes, de se deixar reformar ao seu contato; ela não deve tentar pensar a percepção, mas pensar segundo ela" (Barbaras 4, p. 28-29). ${ }^{2}$

A reformulação e a reestruturação do problema da percepção me parecem o eixo central a partir do qual é possível compreender a nova solução proposta por nosso autor. Tal problema deve ser posto e situado entre as duas dimensões ou elementos que caracterizam e exprimem a experiência perceptiva: a transcendência e a imanência. Por um lado, encontramos na percepção um modo de acesso à realidade tal como ela aparece em si mesma, através dela tomamos contato com algo que já se encontrava aí antes de nós. Por outro, somos nós mesmos que fazemos tal experiência, ou melhor, é inegável que quem faz esta experiência é o próprio sujeito da percepção através de seus órgãos dos sentidos. Eis o modo como Barbaras formula o problema em questão: "como é possível partir de estados subjetivos, imanentes e, portanto, relativos, e ter acesso a isto que repousa em si e é relativo apenas em relação a si mesmo? Como pode o vivido alcançar uma coisa espacial que lhe é profundamente estranha?” (Barbaras 3, p. 35). Para o filósofo devemos conciliar estas duas vias aparentemente contraditórias: o fato de que a percepção se faz aqui no mundo e de que sou eu mesmo quem faz tal experiência. Para compreender a conciliação proposta é indispensável partir e ater-se à experiência imediata, pois "a experiência é esta conciliação" (Barbaras 3, p. 34). Isto significa que não podemos mais submeter nem o objeto da percepção, nem o sujeito da experiência às categorias metafísicas disponíveis. Na verdade, "é a própria percepção, enquanto originário acesso à realidade, que pode libertar o sentido" (Barbaras 3, p.35). Para apreendermos o sentido de ser do real devemos mergulhar nele através da percepção, já que é através dela que temos a iniciação à coisa e ao seu significado.

Se procurarmos acessar a percepção através de algo que ela não é, nós a perderemos, ou antes, nós não a encontraremos. É isto que ocorre com a tradição. Sob a rubrica do empirismo e do intelectualismo a tradição opera com um duplo gesto: por um lado, ela reduz a percepção à outra coisa que ela mesma e, por outro, fecha-se no interior do círculo vicioso das alternativas ao desmembrar a unidade prévia. Trata-se de soluções abstratas que não nos dão a percepção efetiva e que, na verdade, põem em relevo, por contraste, não só a oposição, mas, principalmente, a cumplicidade do empirismo e do intelectualismo em função de um prejuízo muito profundo. Atendo-se ao resultado da percepção - o objeto percebido (a coincidência com a qualidade sensível no empirismo e a adequação intelectual do 
espírito ao significado no intelectualismo) -, a tradição conclui daí que há uma plenitude da coisa. O modelo do objeto é, então, projetado sobre a experiência: "a presença [da coisa] é sinônimo de plenitude" (Barbaras 3, p. 59). A determinação do objeto passa, assim, a caracterizar o ser daquilo que é. Apenas de modo pleno a realidade pode ser dada, apenas enquanto preenche a consciência de ponta a ponta é que a coisa se apresenta. Este ponto de vista põe em relevo a ontologia do objeto submissa ao princípio de razão suficiente. A realidade segundo esta ontologia se caracteriza a partir da velha questão "por que existe algo antes que nada?". Segundo Barbaras, na esteira de $A$ evolução criadora de Bergson, não podemos pensar o ser como se ele se destacasse sobre o fundo do nada. O que temos aqui é, na verdade, um "falso problema" que "se cristaliza no uso do princípio de razão suficiente" (Barbaras 4, p. 66). ${ }^{3}$ Dizer que o ser é mais que o nada, que o ser resiste ao nada, é pensá-lo como uma realidade lógica. Isto implica, necessariamente, pensar o ser como objeto, como positividade, enquanto o nada seria o negativo. Eis aí a contrapartida da interpretação do ser como determinado, a saber, a compreensão da existência em uma localização espaço-temporal que não repercute em nada no pensamento; existir seria, apenas, estar situado em algum lugar. A consequência disto está em que a consciência é reconhecida como o lugar apropriado para a essência. Compreende-se, então, que para a tradição haja sempre um abismo entre a essência e aquilo que a manifesta. ${ }^{4}$

Retomemos o problema da percepção: com que arsenal conceitual enfrentar o paradoxo que afirma, por um lado, que a percepção é percepção de alguma coisa e, por outro, que esta coisa sempre aparece para alguém? Formulado desta maneira podemos antecipar a importância dos trabalhos da fenomenologia, já que para esta escola há uma ambiguidade característica da percepção que não permite àquele que a analisa abrir mão de nenhum dos dois lados, pois se é verdade que a "realidade percebida escapa da subjetividade à medida que a percepção é percepção das coisas mesmas", é verdade, também, que a percepção "remete à subjetividade já que as coisas não possuem realidade fora da sua percepção" (Barbaras 8, p. 149). Segundo Barbaras, foi Husserl quem encontrou a percepção e a interpretou no sentido de uma intencionalidade específica, propondo, com isto, um novo modo de resolver o problema da unidade e da multiplicidade, do sentido e do sensível. "Husserl foi o primeiro a ter reconhecido e evidenciado a especificidade da percepção - intuição doadora originária que é, a este título, fonte de direito para o conhecimento - e, consequentemente, a sua irredutibilidade à sensação ou à intelecção" (Barbaras 3, p. 7). ${ }^{5}$ Ora, para apreendermos a especificidade da percepção é preciso lembrar a teoria husserliana da doação do objeto por perfis (Abschattungen), momento em que nosso autor nos recorda que o conceito de perfil nomeia uma "dupla relação": "o perfil apresenta o 'modelo' (o objeto), ele introduz o objeto; mas, ele é apenas um perfil, isto é, ele o apresenta de modo parcial, fragmentário. O conceito de perfil nomeia a ambivalência do aparecer: no perfil, algo aparece, de tal modo que sua transcendência se encontra preservada. O que quer dizer que o perfil se apaga ou se ultrapassa em proveito do objeto e, ao mesmo tempo, recobre, vela o objeto ao manter a distância. O aparecer sob o qual a coisa se dá a mim é e não é a coisa: no aparecer, a própria coisa se apresenta, mas como outra que a apresenta" (Barbaras 5, p. 106). A leitura de Barbaras do livro Ideias I de Husserl nos mostra que a teoria da doação da coisa por perfis tem uma dupla frente de ação que poderia nos ajudar a encaminhar o paradoxo da percepção: em primeiro lugar, a função do perfil é de manifestação do objeto, mas isto não significa que o perfil se anule em benefício do objeto. Por isto mesmo, vale observar, em segundo lugar, que o perfil recobre o objeto que, por sua vez, se apresenta sempre como uma ausência. ${ }^{6}$ Por um lado, o perfil apresenta ou desvenda a coisa, por outro, o perfil é parcial, já que mascara, oculta ou dissimula a própria 
coisa. ${ }^{7} \mathrm{O}$ que deve ser reconhecido aqui é a estrutura de doação - abertura e ocultamento da coisa -, que determina eideticamente a percepção. $\mathrm{Na}$ percepção temos acesso ao objeto, mas nunca uma posse exaustiva dele. ${ }^{8}$ Se nem mesmo Deus pode possuir a coisa em sua transparência, isto é, adequadamente, resta que a inadequação e a parcialidade fazem parte da determinação da essência do objeto percebido que não é, por sua vez, um vivido (Erlebnis) cuja essência seria caracterizada pela identidade do ser e do aparecer. Como compreender, agora, o correlato da coisa percebida, ou melhor, como compreender o sujeito para o qual a coisa aparece segundo modos subjetivos de doação? Segundo Barbaras, a resposta husserliana é "decepcionante", pois há uma defasagem entre a descrição da percepção por perfis e a interpretação oferecida por Husserl através da teoria da constituição. Resumindo: é preciso afastar a ideia de que seria a consciência que constitui o objeto da percepção. Não podemos tomar a consciência como ponto de partida, e isto, sob pena de não conseguirmos mais nos afastar dela. O sujeito da percepção não é uma consciência, o ato da percepção não é uma noese, o fenômeno da percepção não é um noema. Para compreender bem isto, é preciso mostrar, como faz Barbaras, que Husserl ainda é tributário do modelo da ontologia do objeto cara a todas as metafísicas clássicas: "Husserl permanece vinculado a uma metafísica da consciência que confere a esta o estatuto de um ser positivo. A certeza de si, própria do eu, é imediatamente interpretada como autodoação, percepção de si, isto é, presença de um objeto, apesar de que este último não seja outro que o próprio vivido" (Barbaras 3, p. 87). Esse é o pressuposto husserliano que deve ser criticado: aqui também o ser se destaca sob o fundo do nada. $\mathrm{O}$ que é o mesmo que dizer que "a fenomenologia husserliana não escapa da metafísica no sentido em que Bergson a entende" (Barbaras 4, p. 66). Seja como for, a especificidade do percebido não é alcançada através do modelo do objeto, assim como a especificidade do sujeito intencional não pode ser reduzida ao ser positivo do vivido. A fenomenologia husserliana da razão permanece "tributária de pressupostos, de categorias, de conceitos, que não são manifestamente tirados da fenomenalidade" (Barbaras 6). Através da exigência de proximidade para com o fenômeno, Barbaras nos alerta para o fato de que há uma arbitrariedade na paleta conceitual de Husserl. O pai da fenomenologia não retira seus conceitos da estrutura daquilo que é descrito: "Husserl se impede assim de pensar até o fim a percepção, todavia, ele foi o primeiro a notar sua especificidade” (Barbaras 3, p. 88).

Se o sujeito da percepção não é a consciência, quem ele poderia ser? Profundo conhecedor da obra de Merleau-Ponty, Barbaras faz uma revisão da solução que enfrenta o problema da percepção a partir da relação do corpo próprio com o mundo percebido. Para o autor de $O$ primado da percepção e suas consequências filosóficas, "perceber é tornar presente algo com a ajuda do corpo, a coisa tendo sempre seu lugar em um horizonte de mundo, e a decifração consistindo em colocar todos os detalhes nos horizontes perceptivos que lhe convêm" (Merleau-Ponty 20, p. 104). O próprio Merleau-Ponty nunca imaginou formular uma filosofia da percepção sem aproximar-se dos seus desenvolvimentos concretos. Barbaras nos mostra que, ao trabalhar com as categorias da filosofia fenomenológica e com os resultados da psicologia da forma, MerleauPonty interpreta o sujeito da percepção como corpo próprio que encarna a consciência e cujo correlato é o mundo vivido. Porém, mesmo em textos como $O$ visivel e o invisivel, "falta uma teoria da subjetividade perceptiva que seja adequada à estrutura do campo fenomênico" (Barbaras 3, p. 13). Mais ainda: Merleau-Ponty permanece

tributário até o fim da dualidade inerente ao conceito de corpo próprio, dualidade do interior e do exterior, da consciência e da exterioridade: o corpo permanece o 'veículo do ser-nomundo' e a consciência 'o ser para coisa por intermédio do 
corpo'. Mais precisamente, ele reconhece uma dimensão de existência original, da qual deriva a possibilidade da percepção, mas não chega a descrevê-la senão a partir do corpo próprio, isto é, da dualidade negada, e então reconhecida, da consciência e da exterioridade (Barbaras 3, p. 13).

O que redunda, enfim, em uma espécie de denegação que exprime o caráter inconsciente dos prejuízos... É verdade que Merleau-Ponty formula de modo magistral o problema da percepção, "vemos as coisas mesmas, o mundo é aquilo que vemos", diz a primeira frase de $O$ visível $e$ o invisível. Mas, segundo Barbaras, Merleau-Ponty só supera a dualidade reconduzindo-a para dentro de um dos dois pólos.

Como Husserl, Merleau-Ponty procura construir a relação a partir de um sujeito cuja bipolaridade (empírico transcendental) não é colocada profundamente em questão, ao invés de interrogar o sujeito a partir da relação perceptiva: o único passo ulterior em relação a Husserl consiste no fato de partir de um sujeito encarnado, mais do que de um puro sujeito transcendental, mas o método permanece definitivamente o mesmo (Barbaras 3, p.15).

Que se perceba que o objetivo e o sentido da crítica que Barbaras faz à filosofia merleau-pontiana está em que através da experiência singular do corpo acabamos sendo reconduzidos a uma filosofia da consciência ou do vivido cujo escopo é o dualismo e o idealismo.

$\mathrm{Na}$ esteira de Patočka, Barbaras procura neutralizar ao máximo o vivido. É apenas a partir deste ponto de vista que podemos compreender que "a passagem através do vivido do nosso corpo não permite avançar um só milímetro na experiência da percepção" (Barbaras 3, p.16). Esta discussão com o dualismo proveniente da manutenção da filosofia da consciência é importante porque através dela podemos apreender um dos objetivos próprios à filosofia de Renaud Barbaras. Na entrevista à Gallet ele nos diz que a filosofia que lhe interessa não é a filosofia da separação e da dualidade. Aqui, a orientação monista é o ponto fundamental: "penso que o que é satisfatório para o espírito, é sempre ultrapassar a dualidade. Vivo a filosofia como uma exigência de unidade, como uma exigência monista" (Barbaras 6). O interesse de Barbaras pelo monismo exprime uma insatisfação com a fratura e com a imagem tranquilizadora do real derivada do dualismo: "devo confessar que isto me deixa em uma terrível insatisfação e que sempre me preocupei em investigar um plano de unidade" (Barbaras 6).

Se assim for, assumamos o caráter absolutamente prévio do mundo, do "há" prévio que é definido através de uma estrutura de pertencimento constitutiva do aparecer. Ora, esta assunção só pode ser efetivada se abordamos o ser sem o nada interposto, o que significa, por um lado, que é preciso "abordar o aparecer sem objeto interposto, isto é, em sua autonomia" e, por outro, que devemos assumir que toda aparição se dá "sob o fundo de uma realidade ontológica" (Barbaras 4, p. 82). A análise empreendida por Barbaras sobre o aparecer em sua estrutura e autonomia visa ao mesmo tempo uma abolição do privilégio do "subjetivo" e uma crítica radical da atitude "transcendentalista" (Barbaras 4, p. 86). Resumindo ao máximo, poderíamos dizer que sua análise sobre a estrutura do aparecer - seu verdadeiro ponto de partida ${ }^{9}$ - tem três momentos constitutivos: em primeiro lugar, ele nos mostra que todo aparecer implica a coaparição do mundo; em segundo, que o próprio mundo se manifesta em tudo aquilo que aparece; enfim, que há um modo de doação daquilo que aparece enquanto coaparição do mundo: há alguém para o qual o aparecer aparece. Toda esta análise tem por objetivo dar conta da percepção através da autonomia do aparecer (estruturado segundo a estrutura de horizontes) em contraste com 
aquilo que aparece. O sentido desta autonomia está, em primeiro lugar, em que não há mais constituição do mundo pela consciência, não há o vivido, e, em segundo, que o dado fenomenológico fundamental é o campo fenomenal e que o absoluto é a própria a fenomenalidade.

É chegado o momento de começar a interrogar o sentido de ser deste sujeito para o qual há uma estrutura de horizontes, ou seja, para o qual há algo. O sujeito perceptivo é um ser vivo, ele é um sujeito vivo. Este ensinamento Barbaras retira da obra $O$ sentido do sentido de Straus. ${ }^{10}$ Dizer que o sujeito é um ser vivo é o mesmo que dizer que "a percepção é uma modalidade da vida" (Barbaras 3, p. 16), pois em seu mais alto grau de generalidade e neutralidade, a relação que temos com o mundo é uma relação vital, donde o reenvio, agora, da percepção para a vida: "a percepção enraíza-se na vida e deve ser compreendida a partir dela" (Barbaras 8, p. 153). Não se trata, contudo, de nos atermos à diferença entre estar vivo (Leben) e vivenciar uma experiência (Erleben). O que se tem em mira aqui é o fato de que "perceber é vivenciar uma realidade e, portanto, é um modo de viver" (Barbaras 8, p. 153). Porém, Barbaras não assume os ensinamentos de Straus até o fim. É verdade que Straus ajuda o filósofo a sair do "impasse da análise imanente" (Barbaras 3, p. 17), mas ele não chega a reportar a percepção à outra dimensão do que a do conhecimento: a percepção ainda seria interpretada como exterior à vida e ao sentir. Para acessarmos a percepção a partir da vida ou na vida é indispensável termos outra concepção daquilo que é a vida. Esta concepção não é fornecida pelo mecanicismo que lê os processos vitais a partir de leis físico-químicas onde a vida é compreendida a partir do modelo da ontologia do objeto. Neste ponto, Barbaras se inscreve na linha interpretativa que vai de Goldstein a Canguilhem. Aqui, não podemos mais cair na ilusão de que através de análises do tipo físico-químicas alcançaríamos o plano fenomênico; na verdade, tal análise só nos dá conteúdos físico-químicos.
Assim, em um mesmo gesto também afastamos o vitalismo que reporta a vida a uma força ou princípio autônomo irredutível às forças físicas. Como afastar tantos prejuízos? Como evitar as alternativas clássicas do subjetivo e do objetivo que agora aparecem transmutadas na dualidade do mecanicismo e do vitalismo? Se a vida não pode ser apreendida através de uma variação do mundo físico, nem como um princípio de consciência, é porque há uma operação que deve ser efetuada em prol de sua apreensão naquilo que ela tem de mais específico. Se nos aproximamos da vida em sua especificidade, temos a oportunidade compreender, também, a percepção. Porém, somente examinando a fundo a percepção podemos tornar mais claro o sentido da vida. Os conceitos de percepção e vida se esclarecem mutuamente e há entre eles um "mútuo reenvio" e uma "interdependência" (Barbaras 3, p. 18). A este propósito, Barbaras nos ensina que devemos operar uma "dupla redução" que possibilita o acesso à vida enquanto tal. Esta dupla suspensão tem por intenção fazer aparecer a dimensão da vida ou do viver em que se enraizaria a percepção. Enfim, ao nos situar neste plano fenomênico com alcance ontológico é que as alternativas tradicionais aparecem como abstrações tardias.

$\mathrm{Na}$ esteira de Heidegger - que tem o "mérito de ter visto a indigência da biologia científica, mas também filosófica, a respeito da questão do ser da vida", e que apontou "a necessidade de afrontar a vida a partir de si mesma, na sua especificidade" -, Barbaras define o "modo de ser absolutamente específico" da vida como "existencial" (Barbaras 3, p. 20). Aqui, a vida é compreendida "como um modo de relação entre um sujeito vivo e um objeto (um mundo), como um modo de existir" (Barbaras 3, p. 20). A via aberta por Heidegger - a compreensão da vida em seu "sentido primário", ou seja, a vida compreendida "a partir de si mesma em seu conteúdo existencial" (Heidegger 17, p. 249, apud Barbaras 3, p. 21) -, deve ser levada em consideração. Mas, como nos mostra Barbaras, 
é preciso recusar a saída heideggeriana segundo a qual a vida só pode ser pensada a partir do Dasein. ${ }^{11}$ Não se trata de assumir a hipótese de uma ontologia da vida que viria "determinar o que deve haver para que possa ser algo que seja apenas vida" (Barbaras 8, p. 8). Não se trata de assumir a zoologia privativa que perde a especificidade do existir animal ao reportálo a uma teoria da pulsão e do instinto que impede a comunidade com o homem e, enfim, uma determinação existencial.

Em Heidegger, o homem se opõe ao animal como o ser capaz de percepção ao ser em cuja urgência de satisfação pulsional the impede de apreender o objeto enquanto tal. Disto se conclui que é definitivamente impossível, em tal perspectiva, enfrentar a percepção a partir da vida, isto é, a partir do modo de ser do animal (Barbaras 3, p. 23).

A vida em sua singularidade, como modo de existir singular, é que nos fornece o sentido da existência. À zoologia privativa, Barbaras responde com uma "antropologia aditiva" segundo a qual a humanidade se inscreve na animalidade "como sua mais íntima possibilidade": "assim, no modo de existir próprio ao ser vivo (pelo menos animal) deve ser reencontrado a condição de possibilidade da percepção" (Barbaras 3 , p. 24). Doravante, a percepção nos será dada através "daquilo que está presente, pelo menos virtualmente, desde os primeiros estratos da animalidade" (Barbaras 3, p. 24).

Para investigar o modo de existir próprio à vida enquanto ela pode realizar-se na percepção, nosso autor avança em direção a uma fenomenologia da vida. ${ }^{12}$ Barbaras encontra esta fenomenologia na obra de Jonas, o qual lhe permite "afirmar uma continuidade aí onde Heidegger via um abismo e então a afirmar uma prefiguração, no próprio coração do mundo orgânico, da 'visão penetrante' que é atestada na tomada de consciência de si” (Barbaras 3, p. 24-25). Contendo a possibilidade do espírito, a vida também contém a possibilidade da percepção. Jonas foi o primeiro pensador a abordar "o modo no qual a percepção se constitui a partir da vida" (Barbaras 3, p. 27). Primeiramente, notemos que a caracterização que Jonas faz da renovação da matéria no ser vivo através do metabolismo "implica uma transcendência ativa em direção ao mundo: o excesso da forma sobre a matéria é, ipso fato, abertura ao mundo" (Barbaras 3, p. 26). Portanto, a relação com o mundo exterior ainda pode ser expressa através do conceito de intencionalidade. Jonas pensa a vida como um "excesso dinâmico em relação à matéria" e com isto ele nos ajuda a compreender que o "excesso do vivente em relação a si mesmo" (Barbaras 3, p. 27) deve ser interpretado à luz do conceito de intencionalidade, isto é, através de sua singular abertura ao mundo exterior. Solução que aos olhos de Barbaras é "metodologicamente satisfatória". Porém, é preciso chamar atenção, em segundo lugar, para o fato de que a "liberdade orgânica" de que fala Jonas se realiza, precisamente, como necessidade, enquanto o vivente é visto através de sua perpetuação. A estrutura da existência vital o existir da vida -, é caracterizado como um metabolismo ("processo para o qual uma forma se mantém idêntica através de uma renovação contínua de sua matéria") que, é verdade, pretende circunscrever uma "liberdade na necessidade ou como necessidade, isto é, uma liberdade dialética" (Barbaras 3, p. 25). Mas, uma vez que a intencionalidade encontra seu fundamento na renovação da matéria, resta que a própria intencionalidade acaba sendo imposta à necessidade vital revelando, então, uma limitação da teoria que pretendia resolver o problema da abertura à "verdadeira exterioridade, isto é, o objeto enquanto tal" (Barbaras 3, p. 28). Barbaras mostra que a insuficiência desta concepção de intencionalidade é decorrente do fato de que o ser vivo é apresentado como uma ipseidade autocentrada, ameaçada de morte e em busca de sua perpetuação e, por isto mesmo, 
Jonas interpreta a vida como metabolismo e necessidade: "para um sujeito sempre já individualizado e separado do mundo, a vida não pode consistir senão em uma conservação de si, isto é, na satisfação de uma necessidade" (Barbaras 3, p. 29). Somente depois de renunciar a definir a vida como necessidade é que podemos entender a "real fundação da percepção na vida". É neste contexto que Barbaras define sua perspectiva filosófica como "vital-existencial", esperando que, com isto, ele possa nos dizer que a vida deve ser concebida como um "modo de ser último e irredutível", isto é, "como a modalidade no interior da qual e pela qual um ser vivo pode constituir-se, individuar-se" (Barbaras 3, p.29).

O sujeito é reconhecido como vivo e motor, o que se compreende pelo fato de que somente os seres vivos estão em movimento. Mas como, exatamente, reconhecer este sujeito vivo em movimento? Renaud Barbaras nos ensina que sua característica mais importante está na sua "aptidão a mover-se" espontaneamente. ${ }^{13}$ Este argumento pretende nos fazer entender que quando nos movemos já não somos mais aquilo que éramos. Donde a relação que não pode passar despercebida entre a percepção e o movimento ou a ação. É justamente aqui que reencontramos uma das ideias fundamentais de Matéria e Memória. Nestas páginas, Bergson interpreta a percepção do ponto de vista da vida, ou melhor, do movimento. Perceber não é contemplar, mas agir. O sujeito vivo que percebe deve ser situado no ponto de vista da ação que não é um processo objetivo que nos reconduz à representação. Por um lado, Barbaras aborda a percepção a partir da vida ou do movimento sem abandonar o conceito de intencionalidade, por outro, ele assume este conceito não no nível da objetividade, mas da correlação entre o real e o sujeito, entre o Ser e o aparecer. Preservando a dimensão vital da percepção através da teoria bergsoniana das imagens ${ }^{14}$ e o caráter intencional da percepção interpretado à maneira husserliana através do $a$ priori universal da correlação, nosso autor concilia Bergson e Husserl. Ele situa sua perspectiva “à igual distância” (Barbaras 4, p. 129) destes dois filósofos. ${ }^{15}$ Há uma correlação tão estreita entre percepção e movimento que poderíamos dizer que o movimento já é uma percepção assim como não há percepção fora do movimento. A relação ativa do sujeito vivo com o objeto é anterior à distinção tradicional entre a ação e o movimento. Tal relação, longe de ser do tipo mecânico ou acidental, é do tipo intencional. O que é o mesmo que dizer, na esteira de Weizsäscker citado por Barbaras, que "perceber é, no fundo, sempre passar a outra coisa" (Weizsäscker 22 apud Barbaras 4, p. 151). Nas palavras do próprio Renaud Barbaras, "a percepção remete ao movimento de que ela é apenas um momento, um ponto de apoio; mas o movimento, por sua vez, remete à percepção sem a qual ele não poderia se orientar e equivaleria a um movimento mecânico" (Barbaras 11, p. 156). O sentido desta afirmação está em que há uma relação essencial entre o movimento e a percepção, pois se é verdade que a vida possui uma dimensão ontológica irredutível, é verdade, também, que tal relação é de ordem espiritual, a qual exprime, por sua vez, modos da totalidade viva.

Não basta definir o ser vivo pela necessidade ou pela satisfação das necessidades vitais, onde seria preciso identificar uma carência cuja satisfação aplacaria a necessidade. Barbaras chama atenção para uma "carência ontológica que não é apenas uma carência provisória de uma parte [de si] mesmo" (Barbaras 8, p. 157-58). Na esteira de Goldstein, ele nos mostra que é "o próprio organismo que envolve uma relação com a totalidade do Ser, em relação à qual ele aparece como incompleto ou derivado". A caracterização do ser vivo a partir de sua finitude faz contraste, então, com o fato de que sua essência não lhe é imanente, mas encontra-se fora dele: a essência encontra-se "na totalidade do Ser". O ser vivo anseia superar sua individualidade e se identificar com a totalidade: "o ser vivo é caracterizado por uma insatisfação que, por definição, não pode ser superada 
já que ele visa uma totalidade impossível, já que a aparição do objeto de sua ânsia equivale à sua desaparição enquanto sujeito" (Barbaras 8 , p. 158). Na necessidade o ser vivo encontra uma decepção ou satisfação que faz cessar a necessidade: ele encontra a totalidade negando-a. Mas há algo que o impede de satisfazer suas necessidades, a saber: "há uma inquietude, uma tensão própria ao ser vivo, que resulta numa mobilidade contínua e impede o preenchimento das necessidades" (Barbaras 8, p. 158). O escopo desta análise é a caracterização da vida como desejo. Mas atenção: não se trata de constatar a obviedade de que o ser vivo tem desejos. Trata-se, ao contrário, de dizer que o desejo é o próprio "modo de existir" do ser vivo. Esta é a "dimensão originária" aquém da diferença entre a representação e o movimento que procura nosso filósofo: "o desejo é a maneira específica pela qual o ser vivo se relaciona originariamente com uma exterioridade, é a forma primitiva e fundadora da intencionalidade. É enquanto desejo que a vida é capaz de dar origem a uma relação com objetos e, portanto, é como desejo que a percepção se enraíza originariamente no ser vivo" (Barbaras 8, p. 158-59). No desejo não há alternativa entre satisfazer ou frustrar uma necessidade. Na verdade, o objeto do desejo aponta sempre para outro objeto. No desejo, o objeto de satisfação intensifica o próprio desejo: a satisfação não é a cessação do desejo, mas sua reanimação. Ao contrário da necessidade que exprime uma falta definida e restaura a completude vital, no desejo a aspiração que o atravessa não é diferente de uma ausência. O objeto do desejo se manifesta, então, sob a forma de uma ausência, porém, nada lhe falta e nada pode preenchê-lo totalmente. O que Barbaras pretende mostrar com esta análise é o reenvio de um objeto a outro muito anterior à representação pelo conceito e ao deslocamento no sentido físico da palavra. Desejar não é diferente de se dirigir ao objeto: o objeto se dá no próprio desejo enquanto movimento que toma posse do objeto. Mas o objeto do desejo não se dá inteiramente, ele permanece ausente: o desejo escapa ao mesmo tempo da ordem espacial do movimento e da ordem psíquica da representação: ele é o fundamento e a raiz dessas duas ordens, no sentido em que ele as torna possíveis. É o dinamismo originário do desejo - movimento não espacial da aspiração ou da tensão que dá conta da articulação entre percepção e movimento (Barbaras 8, p. 160).

A partir do momento em que compreendemos que a forma originária da intencionalidade é o desejo, temos condição de entender que o próprio sujeito sempre se precede a si mesmo e já pertence ao mundo que ele abre: "o sujeito faz parte do mundo que ele condiciona e a Vida nomeia a arché-facticidade do transcendental, envolvimento mútuo do mundo e de sua condição de fenomenanalização" (Barbaras 4, p. 140).

O estatuto do sujeito do aparecer possui uma "dupla dimensão": ele está inscrito no mundo e é condição de sua aparição (Barbaras 4, p. 153). ${ }^{16}$ Já o desejo é aquilo que relaciona

a aparição finita e a coaparição do mundo que ela supõe. Dizer que a percepção é desejo, é dizer que todo ente só aparece como manifestação de um aparessente último que, por sua vez, nunca aparece. O desejo desdobra a Distância constitutiva do sensível; ao aspirar à totalidade, ele abre a profundidade do aparecer (Barbaras 4, p. 152).

Assim, a descrição do desejo faz eco à percepção como doação por perfis. Lembremos que o objeto percebido nos é dado por perfis que ao mesmo tempo o apresentam e o ausentam. Há, portanto, uma convergência deste fato com a interpretação da "essência da percepção como desejo" (Barbaras 8, p. 160). É partindo do desejo que podemos compreender a doação por perfis, afinal, desejar é tomar uma coisa como expressiva 
de outra que é ausente. ${ }^{17}$ Eis o dinamismo do desejo: aí mesmo onde ele se satisfaz, ele se aviva. Assim como o movimento de reenvio existente no perfil do objeto percebido é ao mesmo tempo presença e ausência, o movimento do desejo deve ser interpretado como apreensão de algo que não se dá inteiramente. $\mathrm{O}$ excesso que caracteriza o objeto percebido é garantido pelo excesso que constitui o desejo. A experiência da percepção como abertura e dissimulação do mundo exterior, a passagem, através do perfil, de uma coisa dada à outra não dada, não se dá fora do movimento do desejo, já que através dele apreendemos algo ao mesmo tempo presente e inacessível. "É por ser desejo, isto é, expectativa absoluta ou carência para além de qualquer objeto definido que a percepção pode acolher a própria exterioridade. É por ser aspiração inextinguível que a percepção é acolhida absoluta" (Barbaras 8, p. 161).

Para terminar gostaria de levantar um dos pontos que a Conclusão do livro $O$ desejo e a distância suscita como uma das direções possíveis de aprofundamento para o tema da percepção, o qual se torna ocasião para repensar o estatuto do tempo e do espaço, a relação entre o desejo e a distância e, enfim, o conhecimento e as significações. Inscrita ou enraizada no interior da vida, a percepção deve ser compreendida a partir da própria vida. É assim que nosso autor preserva a continuidade entre perceber e conhecer. Contanto que não reduzamos ou sujeitemos a vida às necessidades, contanto que não neguemos à vida uma capacidade de negatividade condenando-lhe à positividade, poderemos compreender como o negativo - que não é um puro nada - pode aparecer no mundo. De onde surge a ruptura? "É verdadeiramente a caracterização do vivente como incapaz de negatividade que leva a introduzir um plano perceptivo que rompe com a ordem da vida" (Barbaras 4, p. 166). Vem daí a negação de continuidade entre viver e conhecer. Vem daí, também, o raciocínio inverso: “é na medida em que introduzimos 'o nada no texto da vida' que podemos enraizar verdadeiramente a percepção na vida e, com isto, dar conta da continuidade entre a ordem perceptiva e a ordem cognitiva" (Barbaras 4, p. 166). Reformulando o problema da percepção, Barbaras nos ensina que "enquanto ela já é percepção, a vida porta nela mesma a possibilidade do conhecer" (Barbaras 4, p. 166). O efeito inverso da recusa da interpretação da vida como necessidade é a apreensão do conhecer "aquém da posição de um puro objeto": "se apreendemos o conhecimento a partir de sua dimensão interrogativa que o define em seu fundo, descobrimos sua continuidade com a ordem vital: a interrogação continua a exploração que caracteriza a vida" (Barbaras 4, p. 167). No último trecho deste livro nosso autor nos mostra que a negatividade "surge desde o plano vital" e que a continuidade entre perceber e conhecer deve ser procurada na dimensão interrogativa. $\mathrm{O}$ conhecimento encontra sua raiz no desejo que constitui a vida. Na verdade, desejo e interrogação são sim "um e mesmo movimento". Barbaras chama atenção, então, para uma "dimensão mais profunda" em relação à qual desejo e interrogação, vida e conhecimento aparecem como modalidades. Sobre o pano de fundo da abolição da alternativa entre vida e filosofia retenhamos esta idéia preciosa: "pela interrogação, nos reapropriamos das nossas raízes, nos fazemos vivos” (Barbaras 4, p. 167).

\section{THE PERCEPTION ACCORDING TO BARBARAS}

Abstract: This article presents the concept of perception as well as plays the French philosopher Renaud Barbaras. He starts with the replacement of the problem of perception between immanence and transcendence to indicate the fundamental features that characterize this phenomenon according to his own point of view: the subject of perception as a living subject and the essence of life as desire. It is not for him to approach the perception through what is not. To truly understand the perceived need to let us form with the perceptual experience itself, or rather, one must think according to their perception.

Keywords: Barbaras, perception, movement, desire, life. 


\section{REFERÊNCIAS BIBLIOGRÁFICAS}

1. BARBARAS, R. Merleau-Ponty, Paris: Ellipses, 1997.

2.___. La perception. Essai sur le sensible, Paris: Hatier, 1994.

3. . La percezione. Saggio sul sensibile, Trad. Giacomo Carissimi, Milão: $2002 \mathrm{a}$.

4. Le désir et la distance. Introduction à une phenomenology de la perception, Paris: Vrin, 1999

5. ___ Introduction à la philosophie de Husserl, Chatou: Les Éditions de la transparence, 2004

6. Entretien avec Renaud Barbaras - Propos recueillis par Bastien Gallet [2001]. Disponível em : http://www.musicafalsa.com/article.php3?id_ article $=39$

7. ___ Le mouvement de l'existence. Études sur la phénoménologie de Jan Patočka, Chatou: Les Éditions de La Transparence, 2007.

8. Investigações fenomenológicas. Em direção a uma fenomenologia da vida, Curitiba: Editora UFPR, 2011.

9. . Introduction à une phénoménologie de la vie, Paris: Vrin, 2008.

10. _. Le tournant de l'expérience. Recherches sur la philosophie de MerleauPonty, Paris: Vrin, 1998

11.___ "La phénoménologie du mouvement chez Patočka", in Phénoménologie: un siècle de philosophie, Dir. Dupond, P. e Cournarie, L., Paris: Ellipses, $2002 b$.

12. .Preface", in Simondon, G. Cours sur la perception (1964-1965), Chatou: Les Edition de la Transparece, 2006.

13. BERGSON, H. A evolução criadora, trad. Bento Prado Neto, São Paulo: Martins Fontes, 2005.

14._._. Matéria e memória. Ensaio sobre a relação do corpo com o espírito, trad. Paulo Neves da Silva, São Paulo: Martins Fontes, 1990.

15. CANGUILHEM, G. La connaissance de la vie, Paris: Vrin, 1998.

16. GOLDSTEIN, K. La structure de l'organisme. Introduction à la biologie à partir de la pathologie humaine, Paris: Gallimard, 1983.

17. HEIDEGGER, M. Concetti fondamentali della metafisica. Mondo-finitezzasolitudine, trad. P. Coriando, Genova: Melangolo, 1999.

18. HUSSERL, E. Ideias para uma fenomenologia pura e para uma filosofia fenomenológica, trad. Márcio Suzuki, Aparecida: Ideia\&Letras, 2006.
19. JONAS, H. Le phénomène de la vie, trad. D. Lories, Bruxelas: De Boeck, 2001.

20. MERLEAU-PONTY, M. Le primat de la perception et ses consequences philosophiques, Lagrasse: Verdier, 2004.

21. STRAUS, E. Du sens des sens. Contribution à l'étude des fondements de la psychologie, trad. G. Thines, J.-P. Legrand, Grenoble: Jérôme Millon, 2000.

22. WEIZÄSCHER, V, Le cycle de la structure, trad. M. Foucault, Paris: Desclée de Brouwer, 1958.

\section{NOTAS}

1. Penso, particularmente, nos seguintes textos: "Conscience et perception. Le cogito dans la Phénoménologie de la perception" (Barbaras 10); "Percepção e movimento : o desejo como condição de possibilidade da experiência" (Barbaras 8); "A composição da percepção" (Barbaras 5); "Preface" (Barbaras 12); (Barbaras 1).

2. Dito de outro modo e em outro texto: "uma filosofia da percepção não é só aquela que toma a percepção por objeto, mas é também uma filosofia que se reforma ao seu contato, que pensa segundo a própria percepção" (Barbaras 3, p. 36).

3. Cf. de Bergson, Capítulo IV de A evolução criadora. Barbaras nos lembra que aqueles "falsos problemas" derivam da "inversão das ordens de dependência no seio do real, isto é, de uma decomposição da realidade que não respeita suas articulações efetivas”. Tratase de uma falsa questão "porque ela pressupõe que do nada pode preceder algo, que o Ser pode surgir sob o fundo do nada, o que equivale a inverter pura e simplesmente o estatuto ontológico respectivo do Ser e do nada" (Barbaras 4, p.66).

4. "Só podemos definir a existência como atualização de uma essência sob a condição de compreender esta atualização como representação para uma consciência. Assim aparece claramente, para além de sua oposição aparente, a solidariedade teórica do objetivismo e do subjetivismo: ela se funda sob a decisão implícita de perfilar o Ser sobre o nada" (Barbaras 1, p. 26).

5. "A percepção adquire em Husserl um estatuto primordial já que, ao afirmar que ela é uma intuição doadora de sentido originário, significa que ela entrega o próprio Ser: perceber é ser posto em presença do que é, e a única maneira de alcançar o que é em pessoa, é de percebê-lo. Há reciprocidade entre Ser mostrado como ente e percebido. Segue daí que toda interrogação sobre o Ser passa por uma interrogação sobre a percepção, que o sentido de ser do que é não pode ser alcançado senão em uma eidética da percepção" (Barbaras 4, p. 20). 
6. Em seu livro sobre Husserl, Barbaras formula de modo admirável o mistério envolvido na percepção segundo Husserl: "tal é o mistério do aparecer: algo aparece à alguém; uma unidade transcendente se dá através de uma multiplicidade de vivido. Distinto dos vividos da percepção, o objeto percebido tem necessidade desses vividos" (Barbaras 5, p. 105).

7. "Na percepção, o perfil e o objeto perfilado, a aparição e o que aparece são afetados de uma dupla ambiguidade constitutiva. O esboço é ao mesmo tempo ele mesmo e o objeto que ele apresenta: ele é idêntico a si mesmo e ao seu ultrapassamento (isto é, a seu apagamento). O objeto, por sua vez, é ao mesmo tempo presente, no sentido em que ele é alcançado por alguém, e indefinidamente ausente no sentido em que nenhuma série de perfis pode esgotar seu teor de ser: ele é o idêntico de uma vinda à presença e de um recuo no inapresentável" (Barbaras 4, p. 24).

8. "Assim, com a teoria da doação por perfis, Husserl reconhece que a peculiaridade da coisa é de transcender-me, que o índice da realidade é a exterioridade em relação a consciência, de modo que a percepção, enquanto diz respeito precisamente a uma coisa ou uma realidade, deve oferecer-me tal transcendência, abrir-me a ela. A partir do momento em que a coisa é por essência isto que me transcende e do momento que, por outro lado, nós temos experiência da coisa, não deve haver alternativa entre experiência e transcendência, entre consciência e exterioridade: a percepção designa esta própria unidade através de uma posse e um esgotamento, por isto o problema da percepção não consiste senão no modo de unidade ou de conciliação entre estas duas dimensões aparentemente antagonista, a imanência e a exterioridade" (Barbaras 3, p. 8).

9. “É necessário tomar como ponto de partida a própria estrutura do aparecer e tentar caracterizar o sentido de ser do sujeito (cujo embaralhamento do sentido e do sentir é apenas uma manifestação) a partir desta estrutura, ao invés de se dá-lo inicialmente sob a forma do corpo próprio para daí deduzir depois esta estrutura, como o faz Merleau-Ponty" (Barbaras 4, p.107).

10. O trecho importante citado por Barbaras é precisamente a última frase desta citação: "Podemos observar desde agora sob quais formas [a interpretação do conhecimento humano, a partir do conhecimento perfeito e acabado, que continuamente faz perder de vista os problemas psicológicos do conhecer e do sentir] se manifesta: que na teoria das sensações o sujeito seja transformado em sujeito teórico geral ou em consciência pura e simples; que ele seja objetivado ao ponto de não ser mais senão um receptor de estímulos; que na esteira de Mach, o Eu seja considerado como perdido ou que ele seja interpretado segundo Hume como um feixe de representações; que concedamos, enfim, em todos os atos psíquicos o Eu seja igualmente presente à consciência - em todas essas concepções, o sujeito do sentir não é um homem vivo. Está aí o ponto essencial. Chegamos, assim, através de toda uma série de negações, a uma primeira definição positiva. Concebemos o sentir como um modo do 'ser-vivo' (lebendgs Sein)" (Straus 21, p. 32; negrito acrescentado).

11. Na contramão da tradição que interpreta o homem como "animal racional", Heidegger estabelece a singularidade do Dasein e sua diferença em relação aos outros seres. "É verdade, Heidegger reconhece que a vida pertence à ordem da existência e não da substância, mas ele não pode admitir que a existência seja tal que possa dar conta da existência humana: isto se compreende bem depois da questão ontológica que confere ao homem uma singularidade absoluta, incomparável com qualquer forma de continuísmo. Deriva daí que é a existência humana que deve dar conta, privativamente, da essência vital. [...] Seja como for, a aproximação privativa se traduz em um impasse para a determinação da existência viva. Como se sabe, o animal é caracterizado, por contraste em relação ao homem-formador do mundo (weltbildene), como 'pobre de mundo' (weltlos), e isto significa que o mundo se subtrai na sua própria abertura, dado que a relação do animal como o mundo é um não-haver no interior de um poder-haver. Com isto, Heidegger pretende que, aí onde o homem se reporta ao ser em quanto ser, o animal é obnubilado pela pulsão e como que aprisionado nela, de tal modo que, arrastado em direção de certos seres em vista de sua sobrevivência, o animal não pode nunca alcançá-los enquanto tal: esses se retiram, por assim dizer para trás de suas funções de satisfação da pulsão. É difícil não reconhecer aqui uma orientação teleológica e antropocêntrica, que considera o animal a partir do homem sob a base do modo hierquizante disto que possui apenas instinto e não ainda a consciência" (Barbaras 3, p. 23).

12. Para Barbaras, a fenomenologia da vida tem como tarefa "determinar o que a vida deve ser para que possa ter algo que seja apenas humanidade ou, mais precisamente, o que a vida deve ser para que possa existir um modo de viver que seja consciência de algo" (Barbaras 8, p. 8); sobre o tema da fenomenologia da vida cf. Barbaras 9.

13. "É forçoso constatar que os corpos que percebem são corpos vivos e que eles se distinguem dos outros entes corporais (como, aliás, mas em uma menor medida, desses viventes mais ou menos imóveis que são as plantas) por sua aptidão se mover. É graças a esta motricidade constitutiva do ser vivo que podemos aceder ao sentido último da subjetividade: é enquanto sujeito capaz de movimento que o sujeito perceptivo poderá ser apreendido em seu ser verdadeiro. [...] No seio do 'há', só existe negatividade como mobilidade" (Barbaras 4, p. 108). 
14. Ao afirmar a autonomia do aparecer e ao atribuir ao sujeito uma atividade motora, Barbaras se aproxima das teses do Capítulo I de Matéria e memória, o qual poderia ser lido como uma espécie de fenomenologia da percepção: "recusando tanto a interpretação da realidade no sujeito quanto a posição de uma realidade estranha à experiência perceptiva, Bergson introduz o conceito de imagem para caracterizar o sentido de ser do real. Ele interpreta isto como uma realidade que está situada a meio caminho do objeto espaço-temporal e da idéia: é incontestável que o real não é nada além do que nos aparece (a idéia de uma realidade em si que se situaria atrás do que percebemos é incompreensível) e que aquilo que nos aparece é real (também é inadmissível afirmar que o que nós percebemos está em nós e não uma realidade fora de nós). [...] Trata-se, para Bergson, de dar conta da percepção sem fazer intervir algo como uma representação, isto é, não abandonando o plano, unívoco, das imagens. Em outras palavras, é preciso dar conta da diferença entre o ser e o ser percebido unicamente sob o plano das imagens e, portanto, sem fazer intervir alguma dimensão psíquica, por definição estranhas às imagens. Como nós sugerimos, isto é o mesmo que dar conta da percepção a partir de um sujeito situado no seio daquilo que aparece, isto é, de um ser vivo" (Barbaras 4, p. 121-22).

15. "Nós nos situamos aqui entre Husserl e Bergson: se a percepção é a condição do mundo, esta condicionalidade não pode repousar sobre uma ordem psíquica autônoma e ele deve então proceder da própria atividade vital, de modo que é no próprio movimento que deve ser constituído o mundo que ele supõe como o campo sobre o fundo do qual se desenrola sua potência negadora. Na verdade, esta conclusão procede de uma tomada em consideração rigorosa das condições do problema" (Barbaras 4, p. 131).

16. "Enquanto o sujeito é desejo ele se reporta ao todo do ser e é, então, condição do mundo; mas enquanto o desejo não tem outra realidade que a dos movimentos aos quais ele dá lugar, enquanto sua aspiração se faz exploração, ele está contido no mundo que ele desvela. Em virtude de sua própria essência, o desejo está consagrado a se dispersar em tendências finitas - que podem incluir até as necessidades; sua dimensão transcendental implica seu vir a ser empírico e é por isto que só há desejo como vida. Mas só há desejo como vida porque só há ser constituído do mundo como omni-englobante e logo ao mesmo tempo não-constituível. Assim, abertura conjunta da aparição e de sua retirada na distância, o desejo é a unidade originária da passividade e da atividade: ele só possui o mundo como aquilo que o possui. Porque o ser vivo só existe permanecendo aquém de seu ser, ele só desdobra a totalidade sob a forma daquilo que a nega e não contém o mundo senão como o que o contém: o desejo é o fato do transcendental, ou o transcendental como Fato, a forma concreta de sua retirada originária" (Barbaras 4, p. 153).

17. "Por um lado, ao abrir a profundidade do mundo, o desejo realiza a função de manifestação, torna possível o perfilar do perfil. Mas, por outro, uma vez que ele permanece insatisfação, esta profundidade permanece escondida na aparição, aquilo que aparece se ausenta de sua manifestação e o perfil permanece um perfil, ou seja, também uma esquiva. Pensar o perfilar a partir do desejo, é se dar os meios de compreender que a ausência do perfilado ao perfil não faz alternativa com sua presença e que não há manifestação senão como recuo na profundidade" (Barbaras 4, p. 152). 